\title{
ERRATUM
}

\section{Chapter 9 \\ Mortality Crossovers from Dynamic Subpopulation Reordering}

\author{
Elizabeth Wrigley-Field and Felix Elwert
}

(C) Springer International Publishing Switzerland 2016

R. Schoen (ed.), Dynamic Demographic Analysis,

The Springer Series on Demographic Methods and Population Analysis 39,

DOI 10.1007/978-3-319-26603-9

\section{DOI 10.1007/978-3-319-26603-9_18}

Regretfully an error occurred in Figure 9.2 of this chapter, page 188. The correct figure should read:

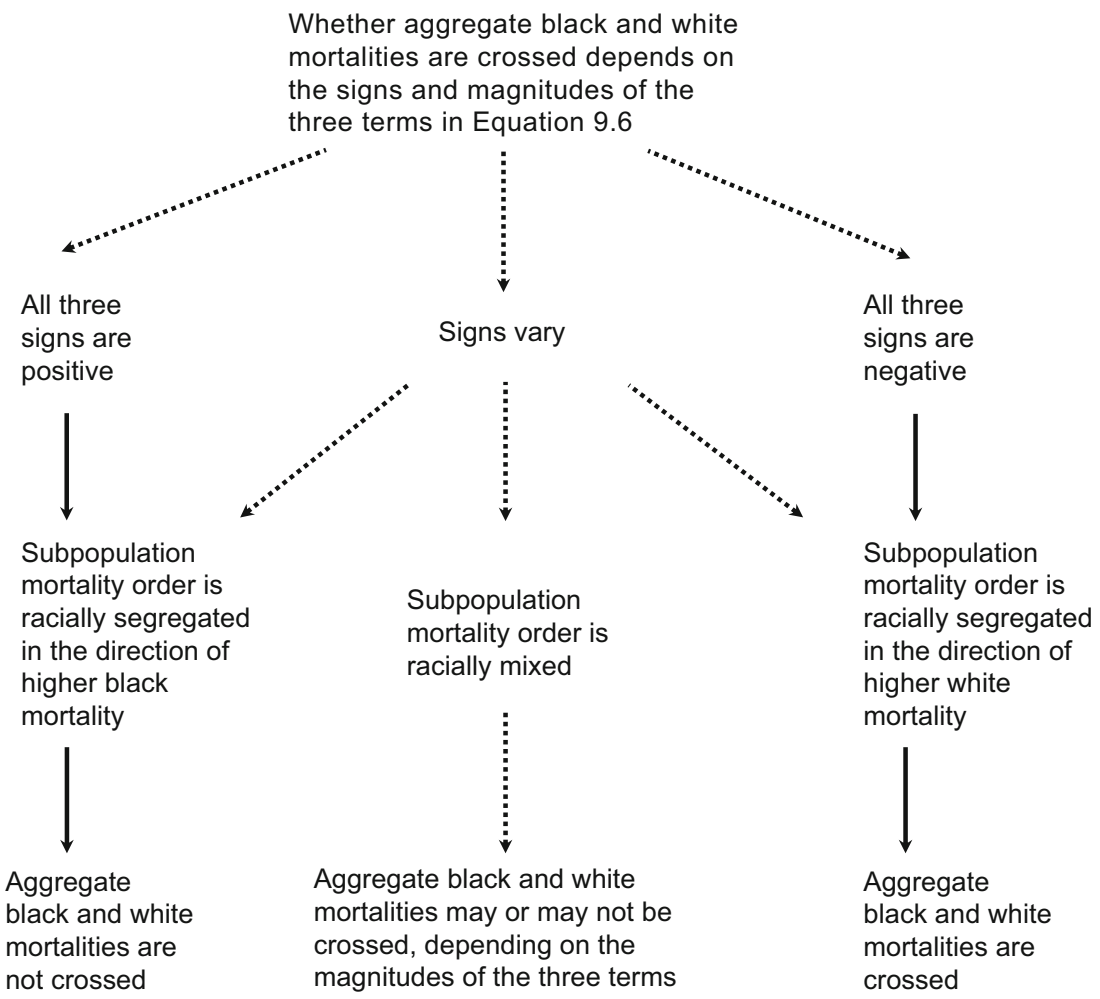

